\title{
Legislação e Automação $\left(^{*}\right)$
}

\section{HANS.JOACHIM VON OERTZEN}

Ministerialrat, Bonn (Alemanha Ocidental)

Tradução de Araújo Cavalcanti

Fonte: Révue Internationale des Sciences Administratives - International Review of Administrative Sciences, 1971, Vol. XXXVII,

n. 3, Bruxelas, Bélgica

INTRODUÇÃO

a) Uma legislação adaptada à automação

b) A aplicação das leis

c) A Lei

I. Possibilidade de automatizar a execução das leis

II. Algumas exigências de uma lei adaptada à automatização
a) A estrutura lógica
b) O caráter condicional ou não condicional da lei
c) A base do cálculo
d) A redução do número dos dados

III. Exemplos concretos com relação às diversas fases do processo

a) A Reunião dos dados

b) $\mathrm{O}$ processamento dos dados

c) A decisão

d) A documentação

(*) Adaptaçăo francesa e atualização parcial de um estudo aparecido em 1969 (in "Deutsches Verwaltungsblatt", pp. 61/67) sob o título Automationsgerechte als Voraussetung der Automation. Faz-se referência apenas ao problema tal como ocorre na República Federal da Alemanha. 
IV. Abordagem da automação no processo legislativo

V. Referências Bibliográficas

NOTA DA REDAÇÃO à Margem das Condições e Perspectivas do

Emprego da Automação no Processo Legislativo.

As modernas técnicas do processamento automático de dados no âmbito da Administração Pública dos países mais desenvolvidos, em face dos avanços tecnológicos da eletrônica, não somente cresceram de importância, como, nestes últimos anos, sofreram um tremendo impacto decorrente da sua generalizada aplicação, e dos consideráveis aperfeiçoamentos recém-introduzidos. Trata-se de uma área extremamente especializada, na qual ocorrem, por assim dizer, diariamente, desenvolvimentos sofisticados, oriundos da denominada "explosão" dos conhecimentos interdisciplinares que convergem, - tanto do ponto de vista das pesquisas científicas puras, como no concernente à tecnologia aplicada, - para 0 fantástico e nebuloso mundo da cibernética e da informática, que já vem provocando, num cenário mundial de transformações aceleradas, os fenômenos identificados por Alvin Toffler como "The Future Schock" (O Choque do Futuro).

O artigo ora divulgado pela Revista do Serviço Público, de autoria de um consagrado analista alemão, Hans-Joachim von OERTZEN (Ministerialrat, Bonn), examina com extrema simplicidade, aspectos da aplicação prática das metodologias e técnicas da automação, no vasto campo do processo legislativo.

Suas considerações abrangem, de um lado, as possibilidades de elaboração de uma legislação adaptada à uma execução automatizada, e de outro, aspectos do processamento eletrônico de dados, com vistas às decisões colimadas.

O assunto, além de ser absorvente preocupação dos governos modernos constitui, ao mesmo tempo, um imenso desafio, teórico e prático, como fator de "aggiornamento" e permanente renovação dos serviços públicos e, muito especialmente, da mentalidade dos administradores, gerentes de projetos, dirigentes ou assessores categorizados. e debates.

A matéria, de há longa data, é objeto de intensas pesquisas

Assim é que, o IIAS - International Institute of Administrative Sciences, sediado em Bruxelas, - promoveu duas reuniőes 
especiais para análise, em profundidade, do problema : a) a Mesa Redonda de Opatija, na lugoslávia, em 1957, que o examinou sob o ângulo teórico; b) a Mesa Redonda de Liège, na Bélgica, em julho de 1958. Nessa ocasião o estudo do problema das condições e perspectivas do emprego da automação nos serviços públicos evoluiu para uma tendência diametralmente oposta, ou seja, uma análise eminentemente prática, versando, inclusive, detalhes técnicos de instalação e funcionamento dos conjuntos eletrônicos, bem como indicações concretas relativas à formação ou adaptação técnica e intelectual do pessoal encarregado da "mise-en-oeuvre" dos programas de automação.

$\mathrm{Na}$ abordagem dos problemas vinculados ao processamento automático de dados no campo da legislação em geral, cabe uma referência especial à terminologia, para uma melhor compreensão no contexto global da administração.

A exatidão terminológica distingue, entre vocábulos e conceitos tão diversos como "mecanização", e "automação", por exemplo. "Automation" - esclarece o Webster's New World Dictionary of the American Language" - "a manufacturing system in which many or all of the processes are automatically perfomed or controlled, as by electronic devices. "Automaton" - 1) anything that can move or act of itself. 2) a person acting in a mechanical way". Esta preocupação se refletia, de resto, nos vários relatórios encaminhados pelos países participantes das aludidas Mesas Redondas de Opatija e Liège. Cronologicamente, distinguem-se as seguintes etapas na organização do trabalho humano: "trabalho manual mecanização - ciclo completo de operações - automação". Um simples trabalho na base de cartões perfurados não pode ser qualificado como "automação". A automação permitirá resolver um certo número de problemas, sem que se possa esperar, contudo, que a máquina seja capaz de, sozinha, equacionar ou avaliar estes problemas. Esta tarefa caberá sempre ao homem que permanece, de qualquer forma, incumbido de duas fases extremamente importantes do trabalho eletrônico: a análise, de uma parte; e a programação, de outra; - isto é, a transcrição, na linguagem das máquinas, do conjunto das operações a efetuar. Apesar das numerosíssimas aplicações da automação na administração em geral, a verdade é que ela ainda se encontra na adolescência, elaborando os seus princípios válidos. As experiências vitoriosas efetuadas, valem como "efeito-demonstração". Encontram-se especialmente neste caso as operações relativas aos pagamentos de salários, aposentadorias e pensões, seguro social, operações de contas na multiplicidade de suas formas, movimentação de correspondência, 
tributação, cadastros, estatísticas, administração de pessoal, comunicações, serviços de telégrafos e telefones, inventários, fornecimentos, traduções, controles múltiplos e auditoria, serviços gráficos etc. e, como teria forçosamente de acontecer, a racionalização do processo legislativo.

Em conclusão, considerada por muitos, há apenas alguns anos, como uma utopia, e por outros, como uma etapa a mais no processo da mecanização, a automação aparece hoje como um elemento novo - indiscutivelmente revolucionário, - cuja força de penetração é tal que os Governos, as Empresas e Instituições, na órbita estatal ou empresarial, dos Países modernos, não mais podem se dar ao luxo de minimizar. A automação é uma pujante realidade concreta, irreversível, que ninguém mais poderá ignorar. O quadro abaixo, baseado nas indicações relativas à análise de 150 casos concretos, dá uma idéia objetiva e preciosas informações quanto às razões que motivaram, pela ordem, o crescente emprego da automação :

1. Aceleração das operações .............. 16,55\%

2. Supressão dos trabalhos de rotina ........... $15,17 \%$

3. Diminuição dos preços de custo . . . . . . . . . $13,79 \%$

4. Informações suplementares ............. $11,79 \%$

5. Aumento das possibilidades de ação ......... $11,03 \%$

6. Melhoria dos controles internos .......... $9,37 \%$

7. Acréscimo de segurança ............... $8,96 \%$

8. Falta de mão-de-obra; liberação de mão-deobra qualificada; humanização do trabalho ... $7,14 \%$

9. Experiência adquirida ou a adquirir ......... $6,20 \%$

$100,00 \%$

Esse levantamento dispensa comentários adicionais e enfatizam os aspectos práticos (Cf. A Administração Pública e os Problemas de Automação, de Araújo Cavalcanti, in RSP, abril de 1959. O mesmo trabalho condensado in "La Scienza e La Technica Della Organizzazione Nella Pubblica Ammnistrazione", Anno VIl, 1960, Gennaio-Marzo, p. 119/120, Roma).

\section{INTRODUÇÃO}

A elaboração de uma lei e a utilização dos computadores para sua execução têm constituído até agora duas operações distintas. Na hipótese de uma execução automatizada, a situação de direito, tal como resulta do texto legal deve ser considerada como fixada. 
O processus de elaboração legislativa escapa inteiramente à ação daqueles que pretendem recorrer ao computador para sua aplicação. Ora, o conteúdo e a forma da lei condicionam a utilização do computador, sua rentabilidade e eficácia.

Torna-se, por conseguinte, desejável, que as necessidades de uma execução automatizada sejam tomadas em consideração desde o estágio inicial da elaboração dos textos, a fim de que se edite uma legislação adaptada à automatização.

Desde já torna-se necessário caracterizar ou definir com exatidão alguns conceitos e a terminologia adotada.

\section{a) Uma legislação adaptada à automação}

Correspondem às exigências deste critério as leis cuja execução, com a intervenção dos computadores, possa atingir ou obter os melhores resultados do ponto de vista da rentabilidade, da rapidez e da exatidão; sobretudo aquelas leis que, no conjunto, foram elaboradas de maneira que as possibilidades decorrentes do emprego dos computadores pudessem ser exploradas ao máximo.

A adaptação a ser efetuada não se limita apenas ao domínio técnico, nem se poderia pretender atingir a perfeição.

Convém levar em consideração todos os fatores, políticos ou outros quaisquer que, em numerosos domínios, são determinantes na concepção, forma ou conteúdo de uma lei, constituindo a otimização colimada uma função desses três fatores.

\section{b) A aplicação das leis}

Ela é a substância, o fato concreto das jurisdições, da administração o mesmo, no direito privado, dos interesses particulares. A não se levar em consideração esse fato, a automatização levanta problemas análogos : por exemplo, o pagamento da remuneração ou salário de um servidor apresenta-se como uma operação semelhante quer seja efetuado por uma empresa privada ou pela administração pública. Em nossa exposição situamo-nos na esfera de execução administrativą, (2) e insistimos quanto a necessidade de uma legislação adaptada à automação; todavia, nossas reflexōes não são, por outro lado, destituídas de interesse para outras modalidades da aplicação das leis.

\section{c) A lei}

A noção exata é aqui tomada no sentido formal e material, como fundamento das regras aplicáveis, abrangendo igualmente regulamentos ou dispositivos administrativos subordinados. O que, por conseguinte, importa adaptar 
à automação, é o conjunto integrado da legislação, tanto no sentido formal como no sentido material - a Lei, os regulamentos, os textos legais, em geral.

Do ponto de vista da execução pelos computadores, as diferenciações ou distinções entre as diversas espécies de normas gerais ou individuais, são destituídas de importância.

Essas distinções entre as normas jurídicas, por vezes sutis, não entram em consideração senão indiretamente, no sentido de que algumas são mais fáceis de modificar do que outras. Quando se fala de uma legislação adaptada à automação, tem-se em vista, desde logo, o conjunto de todas as disposiçōes legais, regulamentares ou administrativas, sem consideração de sua natureza, como base de uma execução automatizada. Disso resulta que nossos propósitos concernentes à adaptação das "leis" (no sentido material e formal) à automação, são igualmente válidos para os regulamentos, as circulares administrativas, as instruções normativas e os atos administrativos individuais, porventura ocorrentes ou tomados na execução de uma lei.

Tornam-se igualmente necessárias algumas indicações a respeito da metodologia e do desenvolvimento do processo.

O princípio diretor é, sempre, a submissão à norma. Uma norma legal no sentido material é concebida de maneira a permitir extrair ou obter conclusões jurídicas de uma situação de fato. Ao aplicá-la o jurista raciocina da seguinte maneira: preliminarmente verifica a existência de uma determinada situação de fato e a confronta com a norma, a fim de verificar se ela corresponde, ou não, a suas condições; em seguida ele decide se pode aplicar, na espécie, a norma, positiva ou negativamente.

A execução administrativa das leis, por sua vez, se opera em condições análogas e consoante uma metodologia intelectual semelhante, todavia enquadrada pelos processos eventualmente utilizados pelos diferentes órgãos.

Com efeito, a administração deve, em primeiro lugar, constatar um estado de coisas, uma situação de fato, confrontá-la com a norma aplicável e, em seguida, decidir, (favorável ou desfavoravelmente, de acordo com o resultado da confrontação). Em administração pública, encerrada esta "démarche", a decisão tomada se concretiza por escrito, conservando-se para registro 0 respectivo "dossier" que é, em seguida, armazenado nos arquivos.

Esquematicamente, o processo é o seguinte :

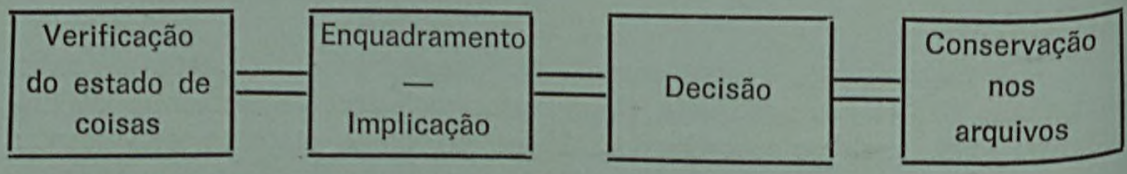

R. Serv. públ., Brasília, 109 (2) abr./jun. 1974 
O processo automatizado de execução apresenta traços peculiares; em primeiro lugar, uma adaptação da lei em função das exigências do trabalho dos computadores, simultaneamente com a tradução da linguagem da lei na linguagem da máquina.

As operações para tal fim comportam três fases : a análise da lei; a programação em função dos resultados desta análise (com, eventualmente, uma experimentação limitada); e, finalmente, a execução mecanizada.

Esta última se efetua em condições semelhantes às da aplicação administrativa clássica. O ponto de partida é, obviamente, a verificação da situação de fato existente que implica ou pressupõe o armazenamento de dados. A confrontação é substituída pelo processamento eletrônico dos dados pelo computador, cujo resultado é a decisão. Os dados essenciais podem permanecer na memória do computador, formando, destarte, uma documentação substitutiva dos arquivos tradicionais.

O esquema será, portanto, o seguinte :

\begin{tabular}{|c|c|c|c|c|c|c|}
\hline $\begin{array}{c}\text { Seleção e } \\
\text { armazenamento } \\
\text { dos dados }\end{array}$ & $\begin{array}{c}\text { Processamento } \\
\text { dos } \\
\text { dados }\end{array}$
\end{tabular}

Estas diversas fases não são inteiramente automatizadas e subsiste uma parte do processamento manual, notadamente, na maioria dos casos, ao nível do armazenamento dos dados. Da respectiva proporção dos trabalhos mecanizados e manuais depende, entre outras conseqüências relevantes, a rentabilidade de uma execução automatizada. Isto não significa que esta seja a mais rentável e mesmo com o desaparecimento de todo o trabalho manual evidentemente esse objetivo colimado é o alvo que se busca atingir, principalmente quando se trata de operações repetitivas e de grande volume ou massa. Isto significa - na hipótese de leis comportando dispositivos de aplicação excepcional em casos raramente ocorrentes - que o recurso ao computador, ou seja, sua utilização nesses casos, deixa de ser rentável. Diante do exposto e por força das importantes despesas concernentes à programação e à memorização, torna-se, então, preferivel, permanecer no trabalho manual; a automação tem os seus campos específicos de aplicação mais vantajosa.

\section{।} ()

Possibilidade de automatizar a execução da lei

Para a administração, a hipótese de trabalho deve ser a de que, em Princípio, toda lei se presta à uma execução automatizada.

Embora isso não seja rigorosamente exato, por motivos técnicos e Práticos, semelhante posição parece ser, no entanto, a mais eficaz para a 
administração : é em cada caso emergente que a administração deverá avaliar ou medir, concretamente, as restrições à automatização. As limitações não deverão ser formuladas a priori; nem as atitudes a adotar deverão ser, da mesma forma, paralisadas, não se levando em conta senão o estado atual da técnica. Na verdade, o desenvolvimento dos computadores, demonstra, há mais de 20 anos que, freqüentemente, aquilo que ontem não se julgaria possível, hoje o é. As impossibilidades de ontem se transformaram nas realidades de hoje. A administração trabalha a longo prazo e deve ser sensível às potencialidades do progresso técnico. Bem entendido, mesmo que se admitisse, em princípio, a possibilidade de uma integral automação das leis, as soluções práticas permaneceriam de qualquer forma ligadas a dois fatores : a estrutura da lei e a rentabilidade.

A estrutura da lei pode ser condicional ou não condicional (3). Certas leis se prestam particularmente bem a uma execução automatizada: aquelas - de estrutura condicional - de que decorrem conseqüências jurídicas imperativas desde que certas condições sejam reunidas. As operações intelectuais da execução se assemelham às operações matemáticas ou lógicas das equações. Outras, pelo contrárìo, denominadas "não condicionais" são completamente insusceptíveis de uma tal execução: ou deixam uma ampla margem a apreciação casuística, ou comportam regras que não são automaticamente exeqüíveis .

A rentabilidade é sempre um fator decisivo. É a razão pela qual os computadores são prioritariamente utilizados para trabalhos repetitivos e de massa, difíceis de serem manualmente executados e que, de outra forma seriam de execução impraticável em prazos mais ou menos curtos. A rentabilidade torna-se então evidentemente imperativa. Ao contrário a não-rentabilidade da automatização das leis de aplicação ocasional que comportam complicados dis* positivos de emprego episódico, é da mesma forma patente.

\section{Algumas exigências de uma lei adaptada à automatização}

Certos fatores são determinantes para a automatização mas apresentam, por outro lado, freqüentemente, um interesse que vai muito além desta preocupação imediata. O principal cuidado consiste em eliminar defeitos, omis. sões, distorções que possam impossibilitar a automatização ou reduzir à nada sua rentabilidade. Nesse contexto, devem ser considerados entre outros fatores, os seguintes:

\section{a) A estrutura lógica}

Tanto no concernente à redação como à apresentação da lei, a estrutura lógica é uma condição fundamental da automatização (4) .

R. Serv. públ., Brasilia, 109 (2) abr./jun. 1974 
As distorções ou defeitos aparecem no preciso momento da análise do texto preliminar a uma eventual execução automatizada, sendo, nesse caso, demasiado tarde para remediar.

Seria, portanto, aconselhável empreender essa análise desde o início, a fim de descobrir e corrigir a tempo, no momento oportuno, os erros ou distorções, na ocasião em que o texto ainda não é senão um esboço ou anteprojeto. Nesse estágio, é igualmente possível fazer experiências de programação e, ao mesmo tempo, controlá-las, pela simulação, a fim de identificar dificuldades que posteriormente poderiam se revelar bastante onerosas.

Pode-se citar como exemplo de legislação bem adaptada à automatização a lei alemã preparatória do recenseamento da população em 1970 (5), que permitiu, antes da adoção do texto definitivo, simulações e estudos metódicos garantindo uma aplicação adequada.

A adaptação à automatização pode acarretar o abandono das práticas tradicionais na economia das leis. Por exemplo, se o exercício de uma determinada atividade é submetido a uma autorização, as condições exigidas para sua concessão são, muitas vezes, deixadas na sombra: indica-se somente as razões pelas quais ela deve ou pode ser recusada. Não é senão indiretamente que se pode deduzir do exame destas razões as condições da concessão. Pode-se indagar se para a adaptação à automatização, não seria preferível agir inversamente, isto é, definir previamente as condições da outorga, justificando-se a recusa pelo único fato de elas não estarem reunidas.

\section{b)}

\section{O caráter condicional ou não condicional da lei}

Este elemento já foi evocado com relação às possibilidades da automatização. Contudo, distinguindo-se entre as leis "condicionais" e "não condicionais", não é preciso limitar ou restringir o exame da lei ao sentido formal $\theta$ material. Quando uma lei (não condicional) deixa uma margem de julgamento na sua aplicação, é preciso ficar atento à medida na qual a livre apreciação pode Ser limitada pelas disposições administrativas de execução. Com efeito, é neste nivel que se editam ou expedem, freqüentemente, instruções tão pormenorizadas que ium conjunto não condicional formado pela lei, o regulamento e a regra administrativa, pode ser, na prática e na realidade, uma lei condicional.

c)

\section{A base do cálculo}

Em toda lei e qualquer lei em virtude da qual se concedeu ou se exigem prestações em numerário, a qualidade da base do cálculo é primordial (6) : sua clareza, sua apresentação, e sua lógica podem ser determinantes no que se refere aos custos de uma execução automatizada. Isto é válido tanto Para as novas leis como para as modificações de textos anteriormente inadaptados. 
Para as novas leis, seria preciso vigiar no sentido de que, na medida do possível, a base de cálculo corresponda às exigências de uma execução pelos computadores. Até agora esse cuidado não tem sido a regra, mas uma exceção.

Os parâmetros e critérios contidos nas leis são estabelecidos, quase sempre, segundo determinadas fórmulas. Quando elaboradas com precisẫo estas fórmulas podem facilitar, enormemente, a execução automatizada (7): se a fórmula for exata e uniformemente aplicada, não será mais preciso memorizar todo o conjunto, sendo bastante a memorização da fórmula, o que aumenta a rentabilidade da execução.

A adequada divisão dos montantes anuais ou mensais ocasiona problemas especiais. Para a adaptação à automatização, fica-se adstrito à uma aproximação : o dia é o trigésimo de um mês, ou o $365^{\circ}$ de um ano. Mais ainda, será preciso que a divisão seja possível, por exemplo, por mês. Um caso de adaptação à automatização neste sentido é o fornecido pelo ligeiro aumento (de DM 562 a 564) na lei alemã do imposto sobre a renda do montante das despesas profissionais para os assalariados, aumento efetuado a fim de tornar o total divisível por doze. Ao ensejo da modificação de leis acarretando pres. tações do Estado, a adaptação da base do cálculo é particularmente importante. Freqüentemente, não se poderá modificar a base original, mas poder-se-ja pesquisar uma solução facilitando a automatização ou tornando-a praticável. Um exemplo pode utilmente ilustrar este aspecto. Houve, recentemente, na Alemanha, uma modificação relativamente importante nas remunerações da função pública federal, enquanto se aguardava a entrada em vigor de outras recentes disposições. O aumento correspondente das pensões pode ser calculado de uma maneira tradicional a partir da reclassificação, segundo determinadas regras, dos beneficiários das respectivas aposentadorias, nos diversos níveis ou graus. Este método implica, para a administração das pensões, em um trabalho considerável, por isso que será preciso, na maioria dos casos, processar novamente os "dossiers". Uma solução adaptada à automatização de. veria se apresentar de uma maneira diversa. Poder-se-ia, por exemplo, calcular até a idade da aposentadoria, as probabilidades de carreira e de remuneraçăo dos funcionários, antes e depois da entrada em vigor dos novos textos. Confrontando-se os resultados, obter-se-ia um dado-base para o aumento proporcional das pensões.

Um caso particular é o das leis corretivas ou modificadoras aumentando as prestações do Estado com efeito retroativo. Isto acarreta despesas excessivas de cálculo como o sublinhou von Berg (8). Uma solução para a execução automatizada seria a de não prever o aumento senão para o futuro, enquanto que para o passado pagar-se-ia uma importância avaliada de acordo com as bases fixadas pela lei corretiva.

R. Serv. públ., Brasília, 109 (2) abr./jun. 1974 


\section{d) A redução do número de dados}

As leis que reduzem o número dos dados na aplicação geral da legislação são as que melhor se adaptam às necessidades de uma utilização racional da automação. Cogita-se, como exemplo, da utilidade de uma lei introduzindo um número nacional de identidade para cada indivíduo. Todas as vezes que se deve tratar das questões individuais (por exemplo, direito fiscal, impostos, pensões etc.) é preciso indicar e memorizar o nome, prenome, o local e data do nascimento, o endereço, o estado civil etc., da pessoa interessada. A utilização uniforme do número nacional de identidade simplificaria grandemente as coisas, admitindo-se, no caso, que bastaria interrogar o computador que forneceria, de imediato, os dados armazenados na sua memória.

\section{Exemplos concretos com relação às diversas fases do processo}

\section{a) A seleção e armazenamento dos dados}

Acentuou-se que neste nivel a parte do trabalho manual era geralmente a mais importante. O legislador pode contudo atuar de maneira a reduzir essa parte.

Tradicionalmente, cada lei utiliza certas definições e uma terminologia própria. Algumas vezes, diversas leis contêm noções ou mesmo dispositivos idênticos, sem sistema de referência comum e nesse caso é preciso interpretá-las de acordo com o seu contexto. O Tribunal Administrativo Federal (Alemanha) não admite a revisão de julgamentos divergentes, em razão da interpretação diversa de dispositivos idênticos, em duas leis distintas (9). Depois da modificação da disposição sobre a admissão da revisão nos negócios concernentes aos funcionários, ou de seu interesse, o referido Tribunal estendeu essa jurisprudência aos casos de dispositivos idênticos nas leis que regem a função pública nos diversos Länder (10). Uma solução adaptada à automatização consistiria em evitar dispositivos idênticos e em trabalhar, na medida do possível, com conceitos excluindo divergências de interpretação.

A referência aos conceitos e definições de outras leis é particularmente importante quando a execução destas leis já é automatizada. Torna-se, então, desnecessário criar noções novas. Por exemplo, o conceito de "renda", "receita", não se emprega unicamente em matéria de impostos, mas em numerosas leis em que a prestação do Estado é influenciada pelo nivel dos recursos do beneficiário. Uma adaptação à automatização seria realizada se se adotasse uma única definição, por exemplo, a da lei do imposto sobre a renda. Isto 'vitaria complicações e operações inúteis.

Uma simplificação da constatação das situações de fato e, conseqüentemente, do armazenamento dos dados, pode, igualmente, resultar de modifi- 
cações de fundo. Por exemplo, as dificuldades na área do direito federal da função pública, oriundas da distinção operada entre o acidente de trabalho e 0 acidente comum, foram evitadas no Estatuto do Pessoal do Conselho da Europa pela supressão dessa distinção. Paralelamente a esta supressão, operou-se, por outro lado, uma distribuição proporcional às regras quanto aos encargos das cotizações do seguro-acidente entre o Conselho e seus agentes. Soluções análogas poderiam conduzir dessa maneira a processos simplificados e, em conseqüência, passiveis de uma melhor adaptação à automatização.

\section{b) $\mathrm{O}$ processamento dos dados}

Muito já se falou acerca da importância da redução da parte do trabalho manual a fim de explorar ao máximo as possibilidades dos computadores $\theta$ a incidência da concepção da lei a tal respeito. Eis aqui mais um exemplo preciso.

O pagamento das remunerações e salários, na função pública comporta uma fase de cálculo dos respectivos montantes e uma outra de liquidação. O montante devido é função do grau e de uma certa escala, considerando-se a antigüidade ou tempo de serviço como fator determinante. O cálculo do tempo de serviço remunerado, previsto na lei federal, é o resultado de um complicado processo, alguns períodos de serviço sendo contados, direta ou indiretamente, por absorção. A absorção é determinada por um ato adminis. trativo especial da mais alta autoridade hierárquica competente para o agente, com participação do ministro federal do Interior. Estas decisões particulares escapam, em uma larga medida, ao processamento mecânico, e não é senáo depois, que a liquidação pode ser inteiramente confiada ao computador. Uma solução de adaptação à automação seria, por exemplo, renunciar ao cálculo individual adotando-se um ponto de referência fixo (uma certa idade ou a data de entrada no serviço público). Ampliar-se-ia, então, consideravelmente, a parte automatizada das operações.

Numerosas leis, por outro lado, prevêm que uma decisão não pode ser tomada senão mediante autorização ou aprovação da autoridade superior, ou mesmo da autoridade federal.

Isto é sempre uma complicação processual, mas, no caso de uma execução automatizada, pode obstaculizar ou anular inteiramente a rentabilidade. Seria então preciso vigiar no sentido da implantação de critérios a fim de evitar a inútil inclusão, sem maiores razões, de dispositivos deste gênero.

Um outro aspecto vincula-se ao regime da verificação das contas que comporta, antes que a decisão seja tomada, um exame prévio. Esta verificaçăo preliminar não é mais concretamente possível no seio de um processo auto. matizado. Poderia ser substituída pela experimentação do programa que dever 
evidentemente, retomar as garantias oferecidas, em caso de processamento manual, pela verificação prévia. Este exemplo basta para demonstrar que a extensão da execução automatizada das leis tornará necessária uma considerável transformação dos dispositivos referentes ao orçamento e à contabilidade.

\section{c) $\mathbf{A}$ decisão}

A decisão, intervindo ao cabo de um processamento automático, levanta numerosas questões jurídicas (11), que se relacionam com a forma exterior da decisão, interessando particularmente a administração. A decisão automatizada não é, por razões técnicas evidentes, assinada. Um agente não pode mais assumir a responsabilidade da conformidade do ato administrativo apondo-Ihe sua assinatura. Tem-se admitido que uma tal decisão não seja mais assinada e o fato foi formalmente consagrado na lei de processo administrativo do Schleswig-Holstein (12).

Pode-se, contudo, perguntar se uma lei federal não deveria dispor, no Plano geral, que as decisões automatizadas não exigem nenhuma assinatura. Com efeito, uma decisão judiciária indo ao encontro da prática até aqui seguida Pela administração teria como resultado bloquear a máquina.

Um problema análogo se coloca no tocante à ortografia dos nomes dos destinatários. Até o momento, os computadores não podem imprimir as vogais munidas de um trema, cujo emprego na língua alemã é freqüente. Deve-se substituir as letras ae, ue e oe. A legislação consagra em benefício do destinatário o direito à transcrição absolutamente correta de seu nome. Seria preCiso examinar a oportunidade de uma adequada solução para os casos relativos ao mencionado problema. O fundamental é que a decisão automatizada, imPrimida pelo computador, tenha um conteúdo compreensivel - que todos possam ler sem dificuldade. Isto pode acarretar um aumento na composição dos Custos. Trata-se, porém, de uma exigência prática cujo atendimento evitará as habituais recriminações, protestos ou críticas contra as decisões desse tipo.

A utilização de números índices somente deveria ser levada em consideração na medida em que se tenha certeza de que os destinatários podem interpretá-los claramente; no caso contrário será preferivel a adoção de um texto completo e não codificado. E isto é possível ao nível da programação. Conviria no entanto examinar a possibilidade de uma consagração legal do Princípio.

\section{d) $\mathbf{A}$ documentação}

No processo administrativo tradicional, a conservação dos dossiers nos arquivos corresponde a uma eventual necessidade de verificação ou de estudos do caráter histórico. No processo automatizado, a memorização dos dados 
relativos aos casos particulares, no âmbito da documentação corresponde a necessidades mais vastas: utilização para orçamentos, estatísticas, análises de conjunto etc. A esse respeito tem se insistido acerca da importância assumida pelo intercâmbio dos dados, notadamente no concernente à identificação das pessoas.

Quanto à documentação (13), uma legislação adaptada à automação deve atender aos critérios de exatidão e de clareza dos conceitos utilizados. Já se disse algo sobre o assunto mas é preciso insistir. Por exemplo, o vocábulo "Amt" apresenta acepções completamente diferentes na legislação relativa à função pública, no direito orçamentário e no direito municipal. Bem entendido, é duvidoso que se possa desenvolver uma linguagem jurídica na qual cada noção tenha exclusivamente um único significado, o que, certamente, eliminaria toda a confusão.

É preciso admitir o fato de que muitas noções idênticas apresentam significados diferentes, mas, para efeito de uma legislação adaptada à automação, deve-se continuar a envidar esforços, na medida do possível, no sentido de não mais introduzir tais noções, erradicá-las, ou, pelo menos, rẻduzi-las nas leis existentes.

\section{Avaliação e exame da automação no processo legislativo}

A adaptação colimada pretende a utilização dos computadores nas melhores condições possíveis e não apenas objetivar uma exploração sistemática e máxima, da técnica. Para a administração, a automação não é um fim em si, mas um meio que lhe permite expandir seus encargos e melhorar sua execução. A adaptação à automação no processo legislativo embora essencial é apenas um fator entre outros a serem considerados. No momento da elaboração de um anteprojeto num determinado ministério são principalmente as necessidades da matéria ou problema em causa que deverão ser harmo. nizadas com as exigências da adaptação ao processamento automatizado. No estágio parlamentar ulterior, são os argumentos políticos os preponderantes. Todavia, mesmo nessa fase será preciso tentar harmonizá-los com uma soluçăo adaptada à automação.

A maior dificuldade consiste freqüentemente na tentativa de compatibilizar a solução colimada com os objetivos de caráter técnico ou político que a ela se opõem. Somente se poderá chegar a uma situação satisfatória se os argumentos políticos ou técnicos convergirem no mesmo sentido.

Parece evidente que para o êxito da adaptação ao processamento automatizada da legislação, como um fator essencial de sua eficácia, todos os que nele tomam parte deverão modificar seus respectivos métodos de trabalho, o que, por sua vez, implicará em uma radical mudança de mentalidade.

R. Serv. públ., Brasília, 109 (2) abr./jun. 1974 
Um projeto de lei adaptado à automação contém regras que escapam ao compromisso e por via de conseqüência, à manipulação; uma decisão política não poderia alterá-las sem que a estrutura lógica de todo, ou de parte do texto, não seja transformada, sacrificando-se, assim, a possibilidade da própria execução automatizada. Certamente pode-se discutir e modificar o fundo ou a substância das proposições legislativas, mas, nesse caso, deve-se instituir uma outra estrutura lógica que não possa ser objeto de manipulações. Em política, o que sobretudo importa, é o resultado, e é ele sempre objeto de discussões e de eventuais compromissos. No que se refere à discussão de projetos de lei adaptados à automação, sob este ângulo, a comparação com a matemática mostra que o debate deve se deslocar dos resultados para as premissas que a elas conduzem. Se as premissas são admitidas com o apoio da maioria, o resultado se impõe forçosamente e não mais pode ser objeto de um compromisso. Se, por exemplo, o aumento do custo de vida for uma determinante na regulamentação uma questão financeira e se o índice dos preços subiu de $4 \%$, por exemplo, este resultado não pode mais ser manipulado. Pode-se, contudo, indagar se a nomenclatura dos elementos entrando no cálculo deste índice foi corretamente constituída. Uma decisão sobre a inclusão dos aluguéis, por exemplo, com uma componente da estrutura dos custos provoca uma mudança das premissas e obter-se-á, então, um outro resultado matemático diferente de $4 \%$. Quem desejar, no curso do processo legislativo, modificar ou substituir um projeto adaptado à automação, deve considerar a mudança com relação ao antigo processo.

A necessidade de adaptar a legislação à automação não se satisfaz unicamente com as diretrizes das novas leis e com supressão das dificuldades encontradas quanto a execução pelos computadores. Sem dúvida estes são objetivos primordiais e imediatos, mas não são os únicos. A adaptação do conteúdo e da forma de todas as leis deve ser o objetivo a longo prazo, o que torna necessária uma revisão progressiva de todas as regras jurídicas. A ação a empreender será tanto mais exeqüível quanto mais se integrar no processo de elaboração dos textos desde o começo. A maior parte dos projetos de leis são de origem governamental, os textos sendo preparados nos ministérios. Se o anteprojeto ministerial opera já uma adaptação à automação - devidamente justificada na exposição de motivos - ter-se-á dado um grande passo. É portanto lógico começar pela soma das experiências e dos conhecimentos em matéria de execução automatizada para, em seguida, difundir os resultados e princípios da nova legislação adaptada. O que, aliás, já se fez na Baviera onde "princípios provisórios para a redação dos dispositivos adaptados à automação" foram baixados pelo governo e publicados no Diário Oficial de 5 de novembro de 1969. A importância de tais princípios ultrapassa o estreito quadro geográfico no qual foram editados, porque definem exigências que, anteriormente, eram ou permaneciam incertas. São princípios que se dirigem a todos os participantes do processo legislativo, e notadamente aos parlamentares, no que diz respeito à elaboração das leis adaptadas à automação. Medidas ou 
"princípios", exclusivamente referentes ao meio governamental e administrativo, não bastam. Convém, antes, desenvolver e generalizar a tomada de consciência do problema entre todos os que participam do processo legislativo. Isto será ainda mais difícil na medida em que, por força da democratização, participem do processo meios ou círculos extra-parlamentares. As tendências dos participantes leva-os a vincular os problemas da redação dos textos adaptados à automação aos aspectos puramente formais, de tal sorte que estes problemas se diluirão diante de outras considerações. O remédio será, portanto, um consenso geral de aceitação da automação na vida administrativa e uma maior difusão das suas conseqüências para a legislação.

\section{Referências Bibliográficas}

(1) - Comparar von Berg, Automationsgerechte Rechts und Verwaltungsvorschriften, Koln \& Berlin, Grote-Verlag, 1968; Klug-Fiedler, Deutsche Rentenversicherung, 1964, p. 259; von Oertzen, Automationsgerechte Gesetzgebung, em "Moder Mittel des Verwaltungshandelns", Godesberger Taschenbuch Nr. 6, 1970; Raisch, Juristenzeitung, 1970, p. 433; Simitis Informationskrise des Rechts aund Datenverarbeitun, Karlsruhe, Verlag C. F. Muller, 1970.

( 2) - Comparar, de modo geral : Bull, Verwaltung durch Maschin Koln \& Berlin, Grote-Verlag, 1964; Klug, Juristiche Logik 3. Aufl., Berlin u.a., 1966, pp. 157 ss.; Luhmann, Recht und Automation in der offentlichen Verwaltung, volume 29 da série da Escola de Altos Estudos Administrativos de Spire, Berlin, 1966; Simitis, Automation in der Rechtsordnung, série da "Juristische Studiengesellschaft", Karlshue, 1969; Zeidler, Ueber die Technisierung der Verwaltung, Karlsruhe, 1969; os relatórios do governo federal de 7 de outubro de 1968 (Bundestagsdrucksache, V/3355) e de 17 de abril de 1970 (Bundestagsdrucksache, V/648) dão informações sobre o emprego dos computadores na administração.

( 3) - Luhmann, Recht und Automation in der offentlichen Verwaltung, p. 36.

( 4) - Podlech, Der Betriebs-Berater, 1968, p. 108.

( 5) - De 28 de abril de 1967 (Bundesgesetzblatt, I, p. 506).

(6) - von Berg, Automationsgerechte Rechts-und Verwaltungsvorschriften, pp. 80 ss.

( 7) - O quadro do imposto de renda se organiza desta forma.

( 8) - Automationsgerechte Rechts-und Verwaltungsvorschriften, p. 78.

R. Serv. públ., Brasília, 109 (2) abr./jun. 1974 
( 9) - Decisões do Bundesverwaltungsgericht, volume 16, p. 53.

(10) - Decisões do Bundesverwaltungsgericht, volume 27, p. 155.

(11) - Comparar a discussão anexada ao estudo de Zeidler Ueber die Technisierung der Verwaltung, en particulier Bull, Verwaltung durch Maschinen, pp. 65 ss.

(12) - § 108 Abs. 3, Landesverwaltungsgesetz de 18/04/1967 (Gesetz und Verordnungsblatt, p. 131).

(13) - Fiedler, Neue Juristische Wochenschrift, 1968, p. 273; Gerstenkorn, Zeitschrift fur das Post-und Fernmeldewesen, 1968, p. 550. 
